\title{
Stage IA Fallopian Tube Cancer AJCC v8
}

National Cancer Institute

\section{Source}

National Cancer Institute. Stage IA Fallopian Tube Cancer A/CC v8. NCI Thesaurus. Code C139985.

Stage IA includes: T1a, N0, M0. T1a: Fallopian tube cancer with tumor limited to fallopian tube surface; no malignant cells in ascites or peritoneal washings N0: No regional lymph node metastasis. M0: No distant metastasis. (AJCC 8th Ed.) 